\title{
Croton faroensis, uma nova Euphorbiaceae da Amazônia brasileira
}

\author{
RICARDO DE S. SECCO ${ }^{1}$
}

(recebido: 27 de junho de 2003; aceito: 5 de fevereiro de 2004)

\begin{abstract}
Croton faroensis, a new Euphorbiaceae from Brazilian Amazon). A new species of Euphorbiaceae from Amazonian Brazil, Croton faroensis R. Secco, is described. This species is similar to C. paraensis Müll. Arg., but differs in having leaves eglandular or with inconspicuous glands at base, with secondary veins forming obscure archs on the lower surface, in the solitary staminate flowers, filaments with villous trichomes, pistillate ones pedicellate and fruits slightly trigonous at the apex. The systematic position of $C$. faroensis in relation to the sections of Croton is discussed.
\end{abstract}

Key words - Croton, Euphorbiaceae, Amazonia, Taxonomy

RESUMO - (Croton faroensis, uma nova Euphorbiaceae da Amazônia brasileira). Uma nova espécie de Euphorbiaceae da Amazônia brasileira, Croton faroensis R. Secco, é descrita. Essa espécie é superficialmente semelhante a $C$. paraensis Müll. Arg., mas distingue-se por apresentar folhas sem glândulas ou com glândulas inconspícuas na base, nervuras secundárias formando arcos pouco evidentes na face abaxial, flores estaminadas solitárias, filetes com tricomas vilosos, flores pistiladas pediceladas e frutos levemente trígonos no ápice. A posição sistemática de $C$. faroensis em relação às seções de Croton é discutida.

Palavras-chave - Croton, Euphorbiaceae, Amazônia, Taxonomia

\section{Introdução}

Croton L. é um dos maiores gêneros das Euphorbiaceae, com cerca de 1.200 espécies nos trópicos e subtrópicos, a maioria distribuída nas Antilhas e América do Sul, e poucas na América do Norte (Webster 1994, Govaerts et al. 2000). Suas espécies são árvores, arbustos, ervas e lianas, geralmente monóicas, algumas vezes dióicas, com tricomas de vários tipos, inflorescências com as flores pistiladas na base e estaminadas no ápice, estames dobrados no botão floral e pétalas das flores pistiladas reduzidas ou ausentes. Desde o tratamento de Müller (1873), as espécies brasileiras não foram revisadas e diversos táxons novos vêm sendo propostos, o que tornou confusa a taxonomia de Croton. Alguns tratamentos recentes sobre as espécies da América do Sul, como os de Cordeiro (1992), Secco (1992), Murillo (1999) e Webster et al. (1999) ainda são insuficientes para que se possa avaliar precisamente os limites específicos em Croton. Nos herbários amazônicos (IAN, INPA e MG) há um grande número de espécimes mal identificados ou indeterminados, o que faz com que o presente estado de conhecimento sobre Croton na região seja bastante precário.

1. Museu Paraense Emilio Goeldi, Caixa Postal 399, 66040-170 Belém, PA, Brasil, rsecco@museu-goeldi.br
Como parte de uma grande revisão do gênero na Amazônia brasileira, foram encontradas coleções procedentes do Estado do Pará, cujas características morfológicas permitem reconhecê-las como pertencentes a uma nova espécie, que a seguir é descrita, comentada e ilustrada.

\section{Resultados e Discussão}

Croton faroensis R. Secco, sp. nov.

Frutex monoicus ramis digitatis dense trichomatibus stellatis obtectis. Folia palmatinervia vel subpinnata eglandulosa. Inflorescentiae bisexualis in racemis digitatis ordinatae. Flores staminate solitarii. Stamina 10-11. Styli multifidi. Fructus apice leviter trigonis.

Figuras 1-7.

Tipo: BRASIL: PARÁ: Faro, lago de Faro, acima de Tanacuera, Igarapé do Infiry, 13-II-1910 (fl., fr.), A. Ducke s.n. (holótipo MG10711).

Parátipo: BRASIL: PARÁ: Oriximiná, margem do rio Mapuera, 30-VI-1980 (fl.), C.A. Cid et al. 1206 (INPA, MG).

Arbusto ca. $3 \mathrm{~m}$ alt., com ramificação dicotômica, indumento de tricomas estrelados, exceto nos filetes, receptáculo e pétalas da flor estaminada (simples, vilosos). Ramos pubescentes, ferrugíneos, ásperos ao tato. Folhas papiráceas a cartáceas, 5-12 cm compr., 


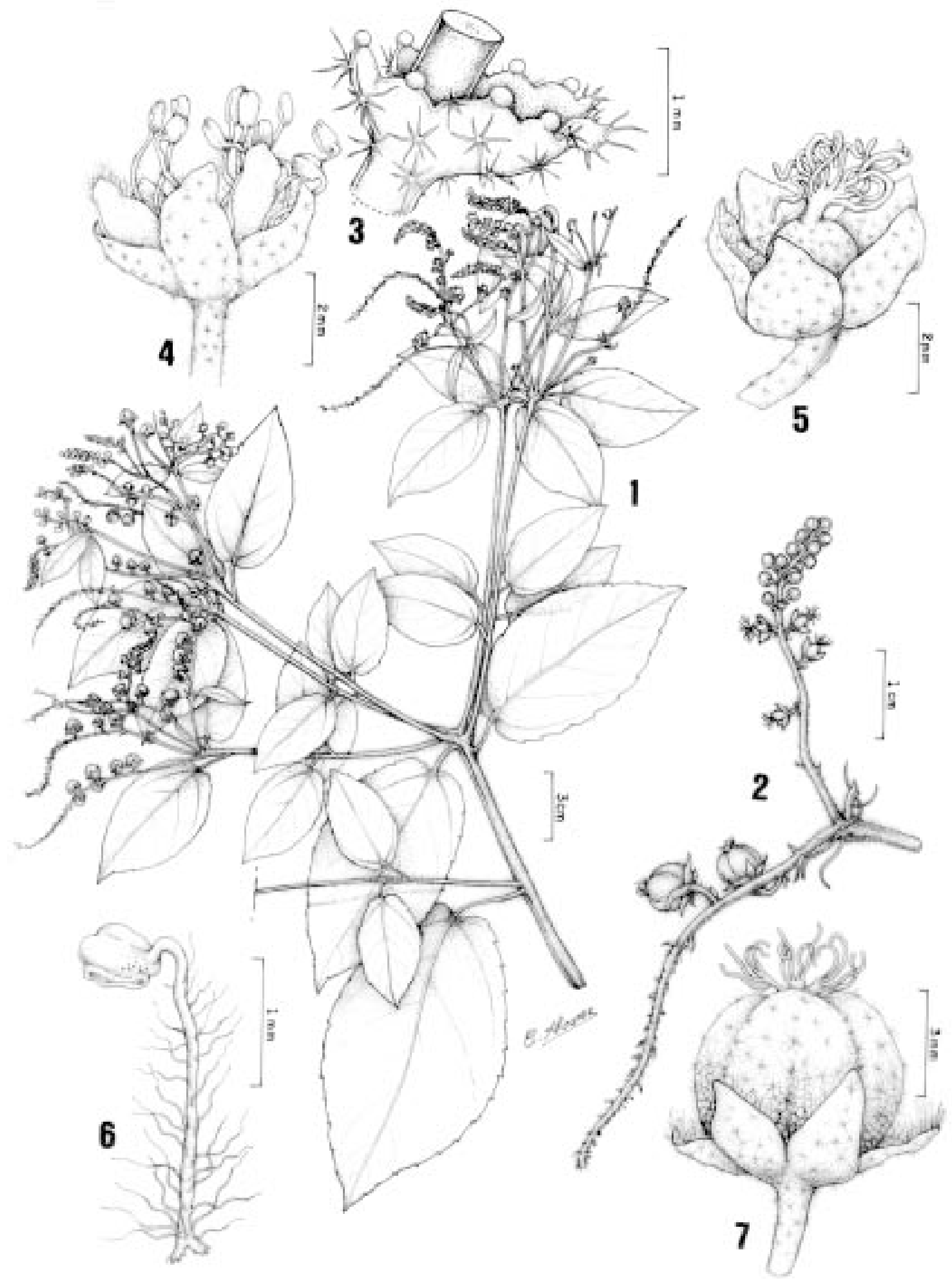

Figuras 1-7. Croton faroensis. 1. Ramo com inflorescências. 2. Inflorescências digitadas, em detalhe. 3. Seção de um pedicelo com um par de bractéolas lobadas, glandulosas. 4. Flor estaminada. 5. Flor pistilada. 6. Estame com tricomas vilosos. 7. Fruto com cálice persistente. (1, 4-5, 7: Ducke s.n., MG 10711; 2-3, 6: Cid 1206).

Figures 1-7. Croton faroensis. 1. Branch with inflorescences. 2. Inflorescences digitate, in detail. 3. Section of a pedicel with a pair of glandular, lobed bracteole. 4. Staminate flower. 5. Pistillate flower. 6. Stamen with villous trichomes. 7. Fruit with persistent calyx. (1, 4-5, 7: Ducke s.n., MG 10711; 2-3, 6: Cid 1206). 
2,5-6 cm larg., palmatinérveas a palmatipeninérveas, elípticas a elíptico-ovadas, com três nervuras na base, as secundárias formando arcos marginais pouco evidentes, especialmente na face abaxial, esparsopubescentes em ambas as faces, com tricomas mais concentrados nas nervuras, especialmente na principal, ápice acuminado, base cordada, glândulas inconspícuas ou ausentes, margem glandulosa, serrilhada; pecíolo 0,5-3 cm compr., densamente ferrugíneo-pubescente. Inflorescências em racemos digitados (umbeliformes), terminais, 5-12 cm compr., raque densamente ferrugíneopubescente, flores estaminadas numerosas, uma por bráctea, 1-2 bractéolas foliáceo-lobadas, glandulosas, na base do pedicelo, pedicelo delgado, 2-2,5 mm compr., pubescente; sépalas 5 , livres, elípticas, ca. $2 \mathrm{~mm}$ compr., pubescentes externamente, glabras internamente; pétalas 5, elíptico-lanceoladas, ca. 2,5 $\mathrm{mm}$ compr., vilosas, especialmente na parte basal interna, glabras externamente; estames 10-11, ca. 2,5-3,5 mm compr., filetes vilosos, receptáculo viloso, disco segmentado. Flores pistiladas isoladas, raramente duas por bráctea, pedicelo espesso, 2-2,5 mm compr., densamente pubescente, bractéolas foliáceo-digitadas, 1,5-2 mm compr., na base do pedicelo, cálice 5-lobado, lobos 3-4 mm compr., triangulares, densamente pubescentes externamente, glabros internamente; pétalas ausentes; ovário globoso, ca. $2 \mathrm{~mm}$ diâm., densamente pubescente, estiletes 3, 2-3-ramificados, ramos 2-3 mm compr., rugosos, pubescentes na base. Fruto cápsula, 6-7 mm diâm., levemente trígono no ápice, pubescente, mericarpos 3, cálice e estiletes persistentes; sementes 4,5 mm compr., rugosas, quilhadas, carunculadas.

Espécie encontrada em campina e campinarana, em beira de mata, nas proximidades do igarapé Infiry e rio Mapuera (Pará), locais com raros registros de coleta na Amazônia.

Por apresentar ramos dicotômicos e folhas cartáceas, com nervação palmatinérvea a palmatipeninérvea, com nervuras secundárias formando arcos, especialmente na face abaxial, Croton faroensis assemelha-se a Croton paraensis Müll. Arg., do Pará e Maranhão. Porém, C. faroensis diferencia-se pelas seguintes características: glândulas ausentes ou inconspícuas na base do limbo, nervuras secundárias formando arcos marginais (na face abaxial) pouco evidentes à vista desarmada, inflorescências em racemos digitados, terminais e axilares, flores estaminadas solitárias, com bractéolas lobadas, filetes com tricomas vilosos, flores pistiladas pediceladas (pedicelo 2-2,5 mm compr.) e frutos levemente trígonos no ápice. Croton paraensis tem glândulas conspícuas na base do limbo, folhas com arcos marginais bem evidentes, inflorescência em racemo não digitado, terminal, flores estaminadas agrupadas em 3-4, com bractéolas inteiras, estames glabros, flores pistiladas subsésseis (pedicelo 0,5-1 $\mathrm{mm}$ ) a sésseis e frutos acentuadamente trígonos no ápice.

Por ser um arbusto monóico, com as folhas sem glândulas (ou inconspícuas) na base, com três nervuras na base, tricomas estrelados, inflorescência bissexuada, sem formar cimas basais bissexuadas, 10 ou 11 estames e flores pistiladas com sépalas inteiras e valvadas, apétalas, sugere-se que Croton faroensis seja posicionada na seção Anadenocroton G.L. Webster, de acordo com o arranjo proposto por Webster (1993), embora referido autor descreva tal seção como tendo "leaves pinnately veined" e a espécie aqui proposta tenha folhas palmatinérveas a palmatipeninérveas.

Agradecimentos - Ao CNPq, pelo auxílio concedido ao autor (processo n. 301.252/86-6) para estudar as Euphorbiaceae da Amazônia; ao desenhista Carlos Alvarez, pelas ilustrações, ao Dr. William A. Rodrigues, da Universidade Federal do Paraná, pela diagnose latina, e aos assessores pelas sugestões ao texto.

\section{Referências bibliográficas}

CORDEIRO, I. 1992. Flora da Serra do Cipó, Minas Gerais: Euphorbiaceae. Boletim de Botânica da Universidade de São Paulo 13:169-217.

GOVAERTS, R., FRODIN, D.G. \& RADCLIFFE-SMITH, A. 2000. World checklist of Euphorbiaceae (and Pandaceae). v.2. Euphorbiaceae: Croton to Excoecariopsis. Royal Botanic Gardens, Kew.

MÜLLER, J. 1873. Euphorbiaceae. Croton. In Flora Brasiliensis (C.F.P. Martius \& A.G. Eichler, eds.). F. Fleischer, Lipsiae, v.15, pars 2, p.82-273.

MURILLO, J. 1999. Composición y distribución del género Croton in Colombia, com cuatro especies nuevas. Caldasia 21:141-166.

SECCO, R.S. 1992. Notas sobre as lianas do gênero Croton L. (Euphorbiaceae). Boletim do Museu Paraense Emilio Goeldi, sér. Bot. 8:265-281.

WEBSTER, G.L. 1993. A provisional synopsis of the sections of the genus Croton (Euphorbiaceae). Taxon 42:793-823.

WEBSTER, G.L. 1994. Synopsis of the genera and suprageneric taxa of Euphorbiaceae. Annals of Missouri Botanical Garden 81:33-144.

WEBSTER, G.L., BERRY, P.E., AMBRUSTER, W.S., ESSER, H-J., GILLESPIE, L.J., HAYDEN, W.J., LEVIN, G.A., SECCO, R.S. \& HEALD, S.V. 1999. Euphorbiaceae. In Flora of the Venezuelan Guayana (P.E. Berry, K. Yatskievych \& B.K. Holst, eds.). Missouri Botanical Garden Press, St. Louis, v.5, p.72-228. 